\title{
Shizuoka Prefecture Disaster Drill Involving the Japanese and US Military
}

\author{
Youichi Yanagawa, MD, PhD; Kazuhiko Omori, MD, PhD; Mariko Obinata, MD; \\ Kentaro Mishima, MD; Kouhei Ishikawa, MD; Hiromichi Osaka, MD, PhD; \\ Yasumasa Oode, MD; Mutsumi Sakurada, MD, PhD; Satoshi Muramatsu
}

$\mathrm{I}$ zu peninsula is in Shizuoka prefecture, which is approximately $130 \mathrm{~km}$ from Tokyo. According to a report from the National Research Institute for Earth Science and Disaster Prevention, Izu peninsula is located just on the border between the Philippine Sea and the Eurasian plate. ${ }^{1}$ In this area, huge earthquakes, called Tokai earthquakes, have occurred repeatedly every 100 to 150 years. The next earthquake is expected to have at least a magnitude of 8 and could cause thousands of deaths, hundreds of thousands of injuries, and millions of damaged buildings, leaving cities that include Shizuoka devastated.

Shizuoka prefecture performed a huge disaster drill on August 31, 2014, obtaining aid from the Japan SelfDefense Forces (JSDF) of the Japanese Military and the US military under an estimation of the occurrence of many isolated areas as the result of road cutoffs due to landslides or debris carried by a tsunami caused by a major earthquake at the end of Izu peninsula. To enable rescue of these areas, training exercises on road restoration, dispatching aircraft or ships for disaster relief, and establishing a system to receive relief quickly from the sky and the sea in the disaster area were the main areas of focus of this drill. A total of approximately 20,000 civilians, public servants, and military personnel participated in this training. Ships including landing craft air cushions were dispatched from the Maritime JSDF and Japan Coast Guard. The 12 ships mainly searched for people set adrift on the sea by the tsunami, carried people and materials for relief, and evacuated people who lived in or were visiting the disaster area. The 24 aircraft, including helicopters, were dispatched from the JSDF, US Air Force, Japan Coast Guard, police, and Shizuoka Hospital, Juntendo University (the East Shizuoka physician-staffed helicopter). These aircraft were mainly used to obtain information about the disaster area, to search for and rescue people adrift at sea, to carry people and materials for relief, and to transport wounded patients. The evacuation of mock severely wounded patients was performed by helicopter to our hospital directly ${ }^{2}$ and to a large parking area near our hospital because the larger helicopters could not land on our rooftop helicopter parking area. Both our hospital and the nearby parking area were identified as one medical staging care unit in this training exercise.,

The governor of Shizuoka prefecture announced the success of these training exercises at the end of the disaster drill. The greatest difficulty was identified to be achieving sufficient communication in different languages and among different organizations. In a catastrophic large-scale disaster, both people and supplies are needed to obtain an early favorable outcome. The coordinated and combined use of military and civilian resources in response to large-scale natural disasters is beneficial and can significantly reduce human suffering. ${ }^{5}$ In Shizuoka prefecture in Japan, all of the participants in the drill, including civilians, public servants, and military personnel, including US military personnel, cooperated in preparation for a huge scale of disaster in the near future. In a catastrophic disaster, the Japanese and US armies would be under the control of the government in each country and would not work preferentially in any one area. The Japanese government has already established a plan in regard to how they will dispatch the Japanese military to disaster areas, including Shizuoka prefecture, when a Tokai earthquake happens. For the US military, we believe that they would cooperate in a manner similar to that experienced for Operation Tomodachi, which was carried out after the 2011 Tōhoku earthquake and tsunami.

\section{About the Authors}

Department of Acute Critical Care Medicine, Shizuoka Hospital, Juntendo University, Japan (Drs Yanagawa, Omori, Obinata, Mishima, Ishikawa, Osaka, Oode); Department of Surgery, Shizuoka Hospital, Juntendo University, Japan (Dr Sakurada); and Division of Community Medicine, Department of Health and Welfare, Shizuoka Prefecture, Japan (Mr Muramatsu).

Correspondence and reprint requests to Youichi Yanagawa, 1129 Nagaoka Izunokuni City Shizuoka, Japan, 410-2295 (e-mail: yyanaga@juntendo.ac.jp).

Published online: June 4, 2015. 


\section{REFERENCES}

1. National Research Institute for Earth Science and Disaster Prevention. Website. http://www.bosai.go.jp/e/. Accessed May 18, 2015.

2. Omori K, Ohsaka H, Ishikawa K, et al. Introduction of a physician-staffed helicopter emergency medical service in Eastern Shizuoka Prefecture in Japan. Air Med J. 2014;33:292-295.

3. Yanagawa Y, Nakamori T, Ishikura K, et al. Japan disaster drill simulates earthquake, medical staging. EMS World. http://www.emsworld.com/ article/11251609/japan-disaster-drill-simulates-nankai-trough-earthquakein-pacific-ocean-and-medical-staging-unit-on-navy-destroyer. Published Nov 27, 2013. Accessed May 18, 2015.

4. Matsumoto H, Motomura T, Hara Y, et al. Lessons learned from the aeromedical disaster relief activities following the great East Japan earthquake. Prehosp Disaster Med. 2013;28:166-169.

5. McCartney SF. Combined Support Force 536: Operation Unified Assistance. Mil Med. 2006;171(suppl 1):24-26. 